\title{
Forming the Trust in Consultation and Medicine Purchase Through Online Application
}

\author{
$1^{\mathrm{st} *}$ Fauzia \\ Communication Science \\ Universitas Indonesia \\ Jakarta, Indonesia \\ fauziaiskandar09@gmail.com
}

\author{
$2^{\text {nd }}$ Firman Kurniawan Sujono \\ Communication Science \\ Universitas Indonesia \\ Jakarta, Indonesia \\ firmankurniawan@yahoo.com
}

\begin{abstract}
Technological development that continue to offer new innovations make people's lives move towards digitization. The increasing amount of mobile phone user also emerge many type of applications that offer various kinds of conveniences, one of them are online-based health. In order to face the era of the industrial revolution 4.0, the health sector must be able to follow developments in digital technology, one of them with health application. Health-based application have high risks and require high trust. The purpose of the study is to find out how application can form the trust with user and how user can trust applications for doctor consultation and purchasing medicine. The research method for this study is qualitative research with a case study approach to health application users.
\end{abstract}

\section{Keywords-application, technology, trust, user}

\section{INTRODUCTION}

Technological development that continue to offer new innovations make people's lives move towards digitization. Many job and human needs are now replaced with technology. The rapid development of digital technology has led civilization into digitization and slowly people are accepting it. Technology offers convenience to fulfill human needs. The increasing amount of mobile phone user also emerge many type of applications that offer various kinds of conveniences. The pattern of information consumption that leads to digitization makes the trend of 'convenience in one hand' (mobile phone) become a necessity.

In 2019, it is estimated that the total population in Indonesia in January 2019 will be 268,2 million with an internet penetration rate of $19 \%$, which Indonesia have great potential in the digital industry. Based on a survey by Tomato Home Digital Indonesia, $79 \%$ of 150 million internet users always use the internet to support their lives [1]. Life support application such as transportation, education, banking, ewallet and health continue to emerge by offering convenience to fulfill their needs. The Google Play Store have more than 1,5 million applications, which were downloaded more than 40 billion times, marking a $60 \%$ increase compared to June, 2013 [2]. In 2019, 390.030 applications were downloaded from Google Play and AppStore within 60 seconds (Lori,Lewis, 2019). Indirectly, technology makes people become dependent on technology.

Initially, the mobile apps were made to meet the needs or support life with a low level of risk and low trust. Nowadays, the digital technology applications are starting to fulfill the needs that require high trust and have a high risk, one of them are the application that provides health service. In Indonesia, many online-based health applications have emerged such as
HaloDoc, AloDokter, KlikDokter, GrabHealth and many more. Most of these applications offers the convenience of accessing health information, consultation with doctor, purchasing medicine to lab tests. The health applications makes face-to-face consultation can be mediated by applications so that activities such as going to health clinic and doctor, waiting in line and purchasing medicine can be done via mobile phone.

The health application is made based on the problem of the gap between the population in Indonesia compared to the number of health workers (doctor, nurse, pharmacist, etc.), uneven distribution of health facilities, difficult access to health facilities, the expensive medical expenses and time needed to access health facilities. Jonathan Sudharta as CEO of MHeatlh Tech, has an idea to facilitate people to access health, and doctor can easily serve the community through the HaloDoc application. Before launching the application, MHealth Tech had built a social network of doctors that has around more than 16 thousand doctor databases and ondemand pharmacy services [3].

In an online-based health application, user can choose the doctor based on their needs and consult with the doctor via chat or video call, then the user can purchase medicine and then the medicine will be directly delivered to the house. With the health applications, face-to-face examination or even initial diagnosis can be done remotely. Health applications are applications that require high trust with high risk because through health applications, face-to-face examination are replaced by chat or video call. In the HaloDoc application, information that related with the doctor are quite transparent by providing information on where the doctors practice clinic, universities where doctors take their courses, the number of 'likes' from users who previously consult with the doctor, the doctor's Registration Certificate number which proves that the doctor is registered and meet the specified requirements. Also, in the HaloDoc application, consultation fee are free or relatively cheap because of the promo. The insurance features made the health insurance can be linked to the application so the user can choose insurance and they don't need to make a payment. In the campaign by HaloDoc, they using \#TanyaDokterAsli to emphasize the purpose of the campaign is to educate the public to access health information from reliable sources.

The digital era makes access to information become unlimited, but it is not supported by good validity. Internet user can easily post information and forward it to other user without restriction and without knowing the source of the information is valid or not. This is become a concern when 
information is related with health such as disease symptoms, medicine and other health advice. With the information, it is feared that the community will diagnose themselves.

At the end of 2019, the world was shocked by the covid19 (corona) virus in Wuhan, China, which then spread to spread to several countries including Indonesia, in March 2020. The large amount of 'hoax' information caused public panic by buying masks and spices because they believe the spices can cure the virus and many other things [4]. The amount of information spread makes people panic and take less-effective action. In this case, HaloDoc, as one of the health-based application, providing information with sources from doctors. One of the articles related to the case is 'Dealing with Corona Virus, Do's and Don'ts' written by Dr. Rizal Fadli. The tendency of people who are easily trust the information and even advice from their closest relatives makes them easily consume the incorrect information. This is also supported by the fact that the medical cost are expensive for some people, the duration needed to waiting in the line to see the doctor and purchase medicine. The high level of community activity makes many people hesitant to see a doctor. The consultant fee is quite expensive so there are many factors that makes the public feel too lazy to consult with a doctor.

The application is considered to be a source to answer the current problem. Changes in the way people access health facilities that were originally face-to-face are now being mediated by the application become more interesting when users trust the consultation process then they purchase the medicine by online transaction while things that relating to health often have a high risk. The researcher are trying to figure out how a health application build a trust between doctor and patient (application user) through the concept of trust.

Trust is an important element in analyzing social relationship. In previous studies, the concept of trust is often used to examine the relationship in online shop purchase, virtual games and banking application. According to Barnes, trust is a person's belief when finding what is desired in the partner, and involves someone to behave in certain way because of they believe their partner will give what they expected and that is based on promises, words or statements of others that can be trusted [5]. To form a trust, according to Morgana and Hunt, high integrity is the most important element [6]. If there are no trusts from buyers and sellers, in this case the users and service provider, there will be no transaction. Since the transaction has become digital or online transaction, it makes trust as an important element. Trust itself happen because of a good reputation, recommendation and experience.

According to Shankar Ganesan, trust is divided into two components, (1) Credibility, which mean the transactions that depend on trust; (2) Benevolence, which is based on partnership trust with the same goal and motivation [7]. Trust is divided into two dimensions, i.e trusting intention and trust belief. Trusting intention is a situation that there is a desire for someone to depend on other parties, in this case HaloDoc users trust their health data to the application by consulting a doctor through the application. There are certain condition where user depend on the application by accepting the risks and consequences [8]. The second dimension is trusting beliefs which measure the extent to which a person believes on something or someone. There are several factors that influence trusting beliefs, such as competence, policy, integrity and predictability [8].

In the process of trust, purchasing decision are determinant of whether a marketing can convince consumer. According to Loebbecke and Hornig, trust in the transaction phase is divided into three phases, and that is:

Information phase is the first phase where consumer actively search for information through internet in order to collect information related to online shop or service based on consumer's need [9].

Agreement phase is the second phase where consumer have shown their agreement by selecting goods/services and also agree to accept the price that have been predetermined [9].

The settlement phase of transaction is the final phase in buying and selling transaction, where consumer have made payment for goods that have been selected for purchase [9].

In purchasing decision, trusts have several types according to Lewick and Bunker, and that is calculus-based trust which is a trust based on economic valuation, then the knowledgebased trust, trust that formed from other party information or advice, and the last one are identification-based trust which mean different people in the same group will tend to behave in way that are more trustworthy by each other when compared to people outside the group [10]. In a relationship, both parties must understand and be able to analyze what is needed or desired by the other party so that the intentions and objectives of the social relationship will form a trust.

\section{RESEARCH METHOD}

The research method for this study is qualitative research with a case study approach to obtain an in-depth understanding of user trust towards the HaloDoc application. In qualitative method, operationalization precedes conceptualization so that ideas and evidence are interdependent [11]. To collect the data, the researcher had done observation and in-depth interview with HaloDoc users. To choose the informant, the researcher was using purposive sampling by limiting the categories of HaloDoc user based on the profession, such as housewives, employees and university student or school student.

\section{RESULT AND DISCUSSION}

Looking at the previous studies, regarding the topic about forming the trust that mostly done in online shop and banking application, which is Forming The Trust In Online Shop by Lingga Detia Ananda (2017), it is important to see what if the research object is the health application user, so it can be an input for health communication and marketing so they can gain trust from user. Simplifying the process of examination and purchasing medicine is an excellent solution for the problem in Indonesia. In order to face the era of the industrial revolution 4.0, the health sector must be able to follow developments in digital technology, one of them with health application. The Ministry of Health of the Republic of Indonesia has issued regulations governing teleconsultation and that is the Article 3 Minister Of Health Regulation No. 20/2019, which explain the telemedicine including clinical teleconsultation, it means providing long-distance health 
services to help diagnose, and/or providing management recommendation or advice. Teleconsultation can be in the form of written, voice and or video, and it should be recorded and noted in the medical record as stated in regulation ( Ministry of Health of the Republic of Indonesia, 2019). With the regulations that have been set, user become more confident to use HaloDoc.

Trust can be formed because of a good reputation, recommendation and experience. Trust is an important element in a transaction and becomes one of the supports for a business. Trust formation is also divided into two dimensions and that is trusting intension and trusting beliefs [8]. Trusting Intention is a situation that there is a desire for someone to depend on other parties and Trusting Beliefs measure the extent to which a person believes on something or someone. Trust is also marked by purchasing, in HaloDoc, it mean purchasing medicine. Trust are divided into three phases, and that is information phase where consumer actively search for information related with product or service, then the second phase is agreement phase where consumer have agree and selecting the goods/services and the final phase is the user made payment for service/goods that have been selected for purchase [9].

Based on the observation, HaloDoc always explained that consultation in HaloDoc are provided by real doctors using \#TanyaDokterAsli. Also, the information on the application in the form of STR Number and other specifications was very helpful for user to select doctor that based on their sickness. Based on the interviews with application users from various professions, the three informants stated that the information provided on the application is very helpful to convince them to use the application. The secure transaction process through the e-wallet GoPay makes the payment system more transparent and easier. According to the third informant, which is the student, she stated that she got a recommendation from a friend. The second informant are the employee, and she stated that there was an insurance feature from where she worked and it is linked to the HaloDoc application, making her trust and use the application. The first informant, a housewife, tends to use the application for consultations on family health and access to health articles. She also stated that the clarity of article sources affects her trust. From the three informants, the convenience offered by the application makes them use the application.

The formation of trust is very important because with the expectation, the trust becomes risky. When the expectation cannot be fulfilled, it will cause a disappointment, betrayal and anger. The first informant, IFND, learned HaloDoc application from the HaloDoc booth at the hospital when taking her child to the doctor. Her statement:

I was taking my kid to the doctor and want to purchase the medicine. My kid was sick and there was a long line in the pharmacy. Then I was offered by HaloDoc sales to purchase the prescribed medicine with application and the medicine will be delivered to my house. At first, I didn't trust it but after the sales showed that the application has collaborate with the pharmacy where I purchase the medicine, I finally agree since my kid was sick and it would be dangerous for my kid to wait. Since then, I use the application to search the health information and consult with the doctor whenever me or my kid feel sick. I was scared at first, thinking if the diagnosis will turn out to be false, but I think the diagnosis is right since they provide the doctor's specification as well (IFND, personal interview February 3, 2020).

The second informant is LK, an employee who already has children. Her trust towards the application was originally formed because the collaboration between the company where she worked with HaloDoc so that insurance from the office was linked to the application. LK statement:

Because the features are quite good, I tried to purchase a medicine without a prescription and then it directly delivered to the office so it is really convenient, plus they don't need to pay because they already use insurance. Since the company has collaborate with it, it means the application is trusted, (LK, personal interview February 3, 2020).

The last informant was NH, a student who got information through advertisements on the Juanda Commuterline Station, then recommended by her friend. Based on information from $\mathrm{NH}$ :

At first, I was asked my friends, "What apps is that?" Then my friend said the apps is very convenient since it has a lot of discount, then there are free consultation and if we purchase the medicine, we will get a discount as well. Because my friend reviewed it as good app, and as student, I love discount, so I use it. So far, everything is fine and the doctor are also responsive (NH, personal interview February 4, 2020).

All three informants are female from various professions. Each informant has a different trust process, but they have similarities and that is the application provides their needs and it becomes a solution for them. Barnes, states that trust is one's belief when finding what is desired in the other parties [5]. In the third informant, $\mathrm{NH}$, trusts were formed not only because her needs were met through the application, but also because of the recommendations and experiences from her friend. It is different from LK that trusts the application through the reputation of HaloDoc which collaborate with the company where LK works. All informants expressed satisfaction with the application, so that the trust has begun to form.

Seeing from how user trust and believe with service, LK stated that the doctors in the application have specifications of experience above 5 years and are educated from good universities which is proved that the doctors are compentent. The health article published is the result of the doctor's information by including the doctor's information and profile. To form a trust, the integrity of service provider is important. Integrity is associated with the attribute of being consistent, honest, fair, responsible, helpful, competent and has good behavior [6]. With the transparency of doctor information and the response from doctor, the user can feel comfortable. LK statement:

The response from the doctor was quick. I was asked to explain how I felt and provide a picture of my situation. The doctor was very helpful, from explaining and giving advice regarding my health complaints ( $L K$, personal interview February 3, 2020).

\section{The same thing was stated by NH:}

At that time I had an eye problem, I used HaloDoc and chose an ophthalmologist. The consultation fee with a specialist was only 25.000 consultation fees. The doctor asked me to photograph my eyes. The doctor asked how I feel, like 
a regular consultation, then advise me with a do and don't, after that the doctor gave me a prescription that can be purchased through the application and the medicine was delivered to my house. It was very helpful because at that time I was advised not to leave the house because I need to avoid dust (NH, personal interview February 4, 2020).

The first informant stated that he used the application quite often to access health information such as health articles. IFND statement:

In the past, we often had to go to docter, but now we can search the information from the application, instead of reading the invalid sources since nowadays there are many invalid health article. But sometime when I need to consult, the doctor that I subscribe sometime are not online. Because that doctor has more experience and has more likes. (IFND, personal interview February 3, 2020).

For IFND, they have started to depend on the HaloDoc application. This mean the trust that they formed are trusting beliefs predictability. According to Lewicky and Tomlinson, predictability allows someone who has trust to be dependent [13]. From the use of the application, the convenience and the satisfaction pushes user to become dependent on the application. Of the three informants, they all have used the HaloDoc application to purchase the medicine, which mean all informants had passed the three trust phases from the information phase where users find out the function and reputation of HaloDoc, then the agreement phase where users have choose the services to be used or purchased, by choosing doctor and access the article on the application and then it lead to the medicine purchase, prescribed or not.

Based on type of trust, each informant has differences. From interview, IFND trust were based on interactions with other parties' needs and intentions, when IFND felt that waiting in line to purchase medicine wasting their time, then HaloDoc sales explained the convenience of using HaloDoc and convince IFND that the purpose of the HaloDoc application is match with their needs. Trusts are formed based on knowledge and ability to predict one's needs and preferences. In this type, both parties must understand and be able to analyze what is needed or desired by the other party so that the intentions and objectives of the social relationship will form a trust.

The second informant, LK, has a type of trust based on information, where trust is built through knowledge and information. LK trusts the HaloDoc application because the company where LK works collaborate with the HaloDoc application so that LK feels confident because it is impossible for the company to cooperate with an unreliable application. While the third informant, $\mathrm{NH}$, acknowledged that the basis of interest in using HaloDoc was based on economic, where the application provided many discounts and low consultation fee. On the other hand, $\mathrm{NH}$ also gets information from the friend so that $\mathrm{NH}$ is driven by two types of trust and that is calculus based trust and knowledge based trust.

The user's trust in a HaloDoc application is based on various types. Three informants stated the importance of clear information as the basis to trust the application. The application also answers their needs and with easy access, the user become more interest to use the application. In order to face the era of the industrial revolution 4.0, convenience are the main factors why applications and the digital industry become solution to address the needs of current society.

\section{CONCLUSION}

In the formation of the trust in health application, the information such as doctor's profile, consultation fee, pharmacy, source or author of health article as well as the experience of previous users in using the HaloDoc application affect the level of user confidence. The HaloDoc campaign, which emphasizes that the consultations and articles on the app are coming from real doctor, also successfully convince the users. Complete information is very important to obtain trust from user.

\section{REFERENCES}

[1] D. Agency, "Data Digital Indonesia 2019," Jakarta, 2019.

[2] "The state of play: A look at the growth of Google Play," 2014.

[3] "Halodoc," www.halodoc.com, 2016. .

[4] R. Efendi, "Diburu Masyarakat Karena Corona, Harga Rempah-Rempah di Medan Melonjak," liputan6.com, Jakarta, Mar-2020.

[5] J. Barnes, Secret of Customer Relationship Management. Yogyakarta, 2003.

[6] R. M. Morgan and S. D. Hunt, "The Commitment-Trust Theory of Relationship Marketing,” J. Mark., vol. 58, no. 3, pp. 20-38, 1994.

[7] S. Ganesan, "Determinants of Long-Term Orientation in Buyer-Seller Relationships,” J. Mark., vol. 58, no. 2, pp. 1-19, 1994.

[8] H. McKnight and N. L. Chervany, "What Trust Means in E-Commerce Customer Relationship: An Interdisciplinary Conceptual Typology," Int. J. Electron. Commer., vol. 6, no. 2, 2002.

[9] C. Loebbecke and V. Hornig, "Increasing Trust in E-Commerce: Concept and Examples of Insurance Solution," in 14th Bled Commerce Conference, 2001.

[10]R. J. Lewicki and B. B. Bunker, Trust in Relationships: A Model of Development and Decline. San Francisco: Jossey-Bass, 1995.

[11] W. L. Neuman, Metodologi Penelitian Sosial: Pendekatan Kualitatif dan Kuantitatif. Jakarta: PT. Indeks, 2016.

[12] Kementrian Kesehatan RI, Penyelenggaraan Pelayanan Telemedicine Antar Fasilitas Pelayanan Kesehatan. Indonesia, 2019, p. 5.

[13]R. . Lewicki, E. . Tomlinson, and N. Gillespie, "Models of Interpersonal Trust Development: Theoretical Approaches,Empirical Evidence,and Future Directions," J. Manage., vol. 32, no. 6, 2006. 